OPEN ACCESS

Edited by:

Karen M. Keane,

Galway-Mayo Institute of

Technology, Ireland

Reviewed by:

Nevena Vidovic,

University of Belgrade, Serbia

Ahmed Barkia,

École Supérieure des Sciences et

Techniques de la Santé de

Sfax, Tunisia

Massimiliano Gasparrini,

Marche Polytechnic University, Italy

*Correspondence:

Azalia Avila-Nava

zomi33@gmail.com

tThese authors have contributed equally to this work

Specialty section:

This article was submitted to Nutrition and Metabolism,

a section of the journal

Frontiers in Nutrition

Received: 09 February 2021

Accepted: 28 June 2021

Published: 23 July 2021

Citation:

Guevara-Cruz M, Medina-Vera I,

Cu-Cañetas TE, Cordero-Chan Y, Torres N, Tovar AR, Márquez-Mota C,

Talamantes-Gómez JM,

Pérez-Monter C, Lugo R,

Gutiérrez-Solis AL and Avila-Nava A

(2021) Chaya Leaf Decreased

Triglycerides and Improved Oxidative

Stress in Subjects With Dyslipidemia.

Front. Nutr. 8:666243.

doi: 10.3389/fnut.2021.666243

\section{Chaya Leaf Decreased Triglycerides and Improved Oxidative Stress in Subjects With Dyslipidemia}

\author{
Martha Guevara-Cruz ${ }^{1,2 \dagger}$, Isabel Medina-Vera ${ }^{2,3 \dagger}$, Trinidad Eugenia Cu-Cañetas ${ }^{4}$, \\ Yusef Cordero-Chan ${ }^{4}$, Nimbe Torres ${ }^{1}$, Armando R. Tovar ${ }^{1}$, Claudia Márquez-Mota ${ }^{5}$, \\ José Moisés Talamantes-Gómez ${ }^{5}$, Carlos Pérez-Monter ${ }^{6}$, Roberto Lugo ${ }^{7}$, \\ Ana Ligia Gutiérrez-Solis ${ }^{7}$ and Azalia Avila-Nava ${ }^{7 *}$
}

${ }^{1}$ Departamento de Fisiología de la Nutrición, Instituto Nacional de Nutrición y Ciencias Médicas Salvador Zubirán, Ciudad de México, Mexico, ${ }^{2}$ Tecnologico de Monterrey, Escuela de Medicina y Ciencias de la Salud, Monterrey, Mexico, ${ }^{3}$ Departamento de Metodología, Instituto Nacional de Pediatría, Ciudad de México, Mexico, ${ }^{4}$ Escuela de Salud, Universidad Modelo, Mérida, Mexico, ${ }^{5}$ Departamento de Nutrición Animal y Bioquímica, Facultad de Medicina Veterinaria y Zootecnia, Universidad Nacional Autónoma de México (FMVZ-UNAM), Ciudad de México, Mexico, ${ }^{6}$ Departamento de Gastroenterología, Instituto Nacional de Nutrición y Ciencias Médicas Salvador Zubirán, Ciudad de México, Mexico, ${ }^{7}$ Hospital Regional de Alta Especialidad de la Península de Yucatán, Mérida, Mexico

Chaya is an edible leaf popular in Mexico and Central America because of its high nutritional value. Studies in animal models have demonstrated the beneficial effects of Chaya, which include reduction of circulating lipids and increase in antioxidant activity. However, its hypolipidemic and antioxidant effects have not been demonstrated in humans. Thus, the aim of the present study was to evaluate the effect of Chaya on the lipid profile, lipid peroxidation, inflammation, and peripheral blood mononuclear cell gene expression in a population with dyslipidemia. We performed a single-arm trial in 30 participants with dyslipidemia who consumed $500 \mathrm{~mL}$ of Chaya beverage per day over a 6-week period. Interestingly, we observed a significant decrease in serum triglyceride concentration $(P<0.05)$ and an increase in plasma antioxidant activity and polyphenol concentration $(P<0.005)$ after 6 weeks of Chaya consumption. This was accompanied by a reduction in the oxidative stress marker MDA $(P<0.0001)$ and by an increase in the antioxidant enzyme CAT expression in peripheral blood mononuclear cells $(P<0.001)$. Altogether, our results demonstrate that consumption of Chaya has hypotriglyceridemic and antioxidant effects in subjects with dyslipidemia.

Keywords: Chaya, dyslipidemia, antioxidant activity, oxidative stress, triglycerides

\section{INTRODUCTION}

Dyslipidemia is characterized by abnormal lipid profiles that include increased levels of triglycerides (TG), total cholesterol (TC), low-density lipoprotein cholesterol (LDL-C), and/or decreased levels of high-density lipoprotein cholesterol (HDL-C). Dyslipidemia is one of the most important risk factors in formation of atherogenic plaques and development of cardiovascular diseases (CVD). Furthermore, hyperlipidemia is related to other complications, such as insulin resistance, endothelial dysfunction, hypertension and oxidative stress (OS) (1). In the context of $\mathrm{OS}$, the increase in reactive oxygen species (ROS) promotes the oxidation of different biomolecules, 


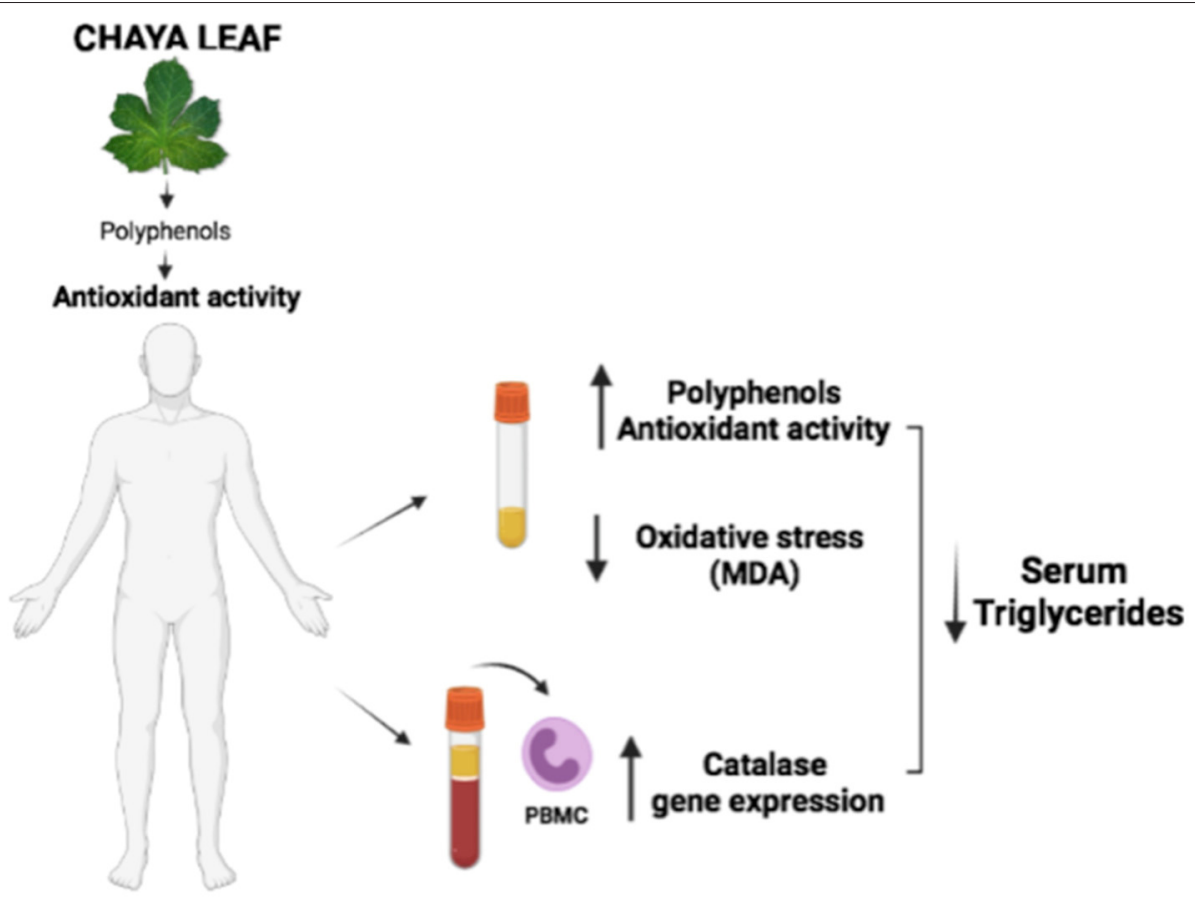

GRAPHICAL ABSTRACT | Effect of Chaya leaf on triglycerides, antioxidant activity and oxidative markers in subjects with dyslipidemia.

such as proteins, DNA, and lipids (lipoperoxidation). Malondialdehyde (MDA) is an end product of lipoperoxidation, which increases the level of pro-inflammatory cytokines such as interleukins and C-reactive protein (CRP) to establish a proatherogenic environment that results in endothelial dysfunction (2). These complications occurring in the context of dyslipidemia are due in part to a decrease in the expression and activity of antioxidant enzymes such as catalase (CAT) and superoxide dismutase (SOD), which enhances OS (3).

One potential strategy to improve lipid profiles is the consumption of foods with a high content of potential bioactive compounds (4). Chaya (Cnidoscolus aconitifolius (Mill.) I.M. Johnst) is an edible leaf popular in Mexico and Central America for its potential use as a vegetable and/or as a medicinal plant. It is widely used as traditional remedy for the treatment of obesity, diabetes, gastrointestinal disorders, and kidney stones (5). Chaya is also an important component of the regular diet of indigenous communities because of its nutritional value; it contains dietary fiber, protein, minerals, vitamins $\mathrm{A}$ and $\mathrm{C}$, flavonoids, and polyphenols. Kaempferol and quercetin are the most abundant phenolic compounds identified in Chaya (6). Studies in animal

Abbreviations: ABCA1, ATP-binding cassette transporter A1 gene; AMPK, AMP-activated protein kinase; BMI, body mass index; BP, blood pressure; CAT, catalase; CRP, C-reactive protein; CVD, cardiovascular diseases; HDL-C, highdensity lipoprotein cholesterol; HMGCR, hydroxy-methyl-glutaryl coenzyme A reductase; HPLC, High-performance liquid chromatography; LDL-C, lowdensity lipoprotein cholesterol; MDA, Malondialdehyde; ORAC, oxygen radical absorbance capacity; OS, oxidative stress; PBMC, peripheral blood mononuclear cells; ROS, reactive oxygen species; SD, standard deviation; SEM, standard error of the mean; SOD, superoxide dismutase; TC, Total cholesterol; TG,triglycerides; WHtR, waist-to-height ratio; 95\% CI, 95\% confidence intervals. models have demonstrated the effects of Chaya, which included reduction of glucose intolerance (7), anti-inflammatory effects, antioxidant activity (8), and hypolipidemic effects (9). These effects are highly great relevant to the current worldwide epidemic of dyslipidemia; however, there are no human studies demonstrating hypolipidemic or antioxidant effects of Chaya. Thus, the aim of the present study was to evaluate the effect of Chaya consumption on the lipid profile, lipid peroxidation, inflammation, and gene expression in subjects with dyslipidemia.

\section{MATERIALS AND METHODS}

\section{Plant Collection}

Chaya (Cnidoscolus aconitifolius (Mill.) I.M. Johnst) was collected in Mérida, Yucatán from March to June 2019. The qualified botanist José L. Tapia-Muñoz identified plant and a voucher specimen (72343) was deposited at the herbarium of the Centro de Investigación Científica de Yucatán.

\section{Chemical Composition of the Beverage of Chaya and HPLC Analysis}

The chemical composition of Chaya was analyzed with techniques recommended by the Association of Official Analytical Chemists (10). Antioxidant activity of Chaya was evaluated by oxygen radical absorbance capacity (ORAC) (11). The total polyphenol concentration was determined in Chaya using the Folin-Ciocalteu method (12). Additionally, we determined the phytochemical profile of a sample of Chaya with High-performance liquid chromatography (HPLC) system (Agilent 7 Technologies 1100) were done using a C18 column 
(Thermo Scientific ODS Hypersil) $(250 \times 4.6 \mathrm{~mm}, 5.0 \mu \mathrm{m})$. For HPLC analysis, a $2 \mathrm{~g}$ dry sample was obtained from beverage. Extraction was carried out using $2 \mathrm{~g}$ of dry sample with $30 \mathrm{~mL}$ of ethanol $(85 \%)$ at $60 \mathrm{kHz}$ in an ultrasonic extraction device, and repeated three times. The extract was stored at $-4{ }^{\circ} \mathrm{C}$ overnight. Then, $15 \mathrm{~mL}$ of methanol and $1.5 \mathrm{~mL}$ of hydrochloric acid were added and left to reflux for $2 \mathrm{~h}$ at $60^{\circ} \mathrm{C}$. The solvent was removed on a rotary evaporator. The dried extract was dissolved in methanol; and approximately $1 \mathrm{~mL}$ of the extraction was filtered through a $0.45 \mu \mathrm{m}$ membrane and transferred into HPLC vials. The sample was eluted at a $1 \mathrm{~mL} / \mathrm{min}$ flow rate with $\mathrm{CH} 3 \mathrm{OH}$ : CH3CN: $\mathrm{H} 2 \mathrm{O}(40: 15: 45)$ as a gradient mobile phase with $1 \%$ of acetic acid and detected by absorbance at $368 \mathrm{~nm}$ using a Waters 2998 photodiode array detector (13). The calibration curves of quercetin and kaempferol (Sigma, St. Louis, MO) were constructed using serial dilutions in ethanol of the standard solution $(0.01,0.05,0.15$, and $0.30 \mathrm{mg} / \mathrm{mL})$. The sample was analyzed in triplicate.

\section{Subjects}

Subjects with dyslipidemia characterized by TG $>150 \mathrm{mg} / \mathrm{dL}$, TC $>200 \mathrm{mg} / \mathrm{dL}$ and/or LDL-C $>120$ and who were aged 20-60 were recruited through advertisements at the Hospital Regional de Alta Especialidad de la Península de Yucatán. Participants did not receive pharmacological treatment for the control of lipids. Exclusion criteria for these participants included $T G \geq$ $350 \mathrm{mg} / \mathrm{dL}$, diabetes, a history of cardiovascular events, and weight loss of $3 \mathrm{~kg}$ within the last 3 months, cancer, acquired immunodeficiency syndrome, kidney or liver disease, smoking, substance abuse, and alcohol consumption. The study was approved by the Ethics Committee of the Hospital Regional de Alta Especialidad de la Península de Yucatán (No. 2018-030), Instituto Nacional de Pediatría (No. 2019/03), and registered at www.clinicaltrials.gov (NCT04110392), and conducted in accordance with the Declaration of Helsinki. Written informed consent was obtained from all participants.

\section{Sample Size}

The required sample size was estimated to be 21 participants based on an expected effect of a $10 \%$ difference with $90 \%$ power and an $\alpha$ error of 0.05 for detecting effects on serum lipids resulting from the consumption of Chaya. The effect size was estimated based on studies of lipid-lowering supplements in patients with dyslipidemia (14), and a loss of $30 \%$ was expected during the study follow up, resulting in selecting 30 participants for enrollment in the study.

\section{Study Design}

The study had a before-and-after design to evaluate the effect of 6 weeks of Chaya beverage consumption in patients with dyslipidemia (Figure 1). At the first visit, a screening evaluation was conducted to select the participants based on the inclusion criteria. Eligible subjects received seven bottles of Chaya beverage to last 1 week. The Chaya beverage was prepared per week as follows: $40 \mathrm{~g}$ of Chaya leaves, which were soaked, disinfected, and mixed with $1 \mathrm{~L}$ of purified water. Finally, $500 \mathrm{~mL}$ of the beverage was placed in bottles and stored at $-4^{\circ} \mathrm{C}$ until consumption

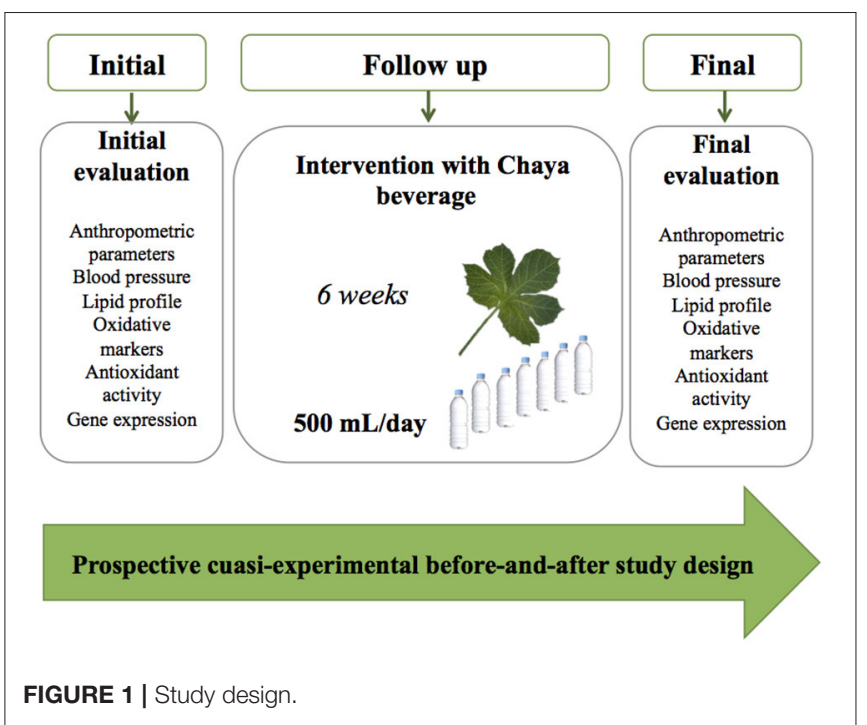

during 1 week. At each visit (weekly), seven bottles and a daily consumption form were given to participants, and the participants were instructed to drink one bottle all at once per day for 1 week and record it on the form. At the end of each visit, participants were asked to return the empty bottles and the daily consumption form. The participants were advised to maintain their normal lifestyle, activity level and diet, and were instructed to restrict the consumption of foods containing Chaya. At the baseline and end of the study, body weight, height, and waist circumference were determined by the Lohman method (15). The waist-to-height ratio (WHtR) was calculated by dividing the waist circumference $(\mathrm{cm})$ by the height $(\mathrm{m})$. Blood pressure was measured with a digital automatic blood pressure monitor (HEM-6122 LA, Omron Healthcare, Inc., Sunrise, FL, USA). Blood samples were collected after $8-10 \mathrm{~h}$ of fasting at the baseline and at the end of the study. Briefly, blood samples were centrifuged at $500 \mathrm{xg}$ for $5 \mathrm{~min}$, and serum and plasma were maintained at $-70^{\circ} \mathrm{C}$ until analysis. Serum TC, TG, LDL-C, HDL-C, and glucose were analyzed with a COBAS C11 (Roche Applied Science).

\section{Oxidative and Inflammation Markers}

Serum MDA concentration was measured as a marker of lipid peroxidation by a spectrophotometric method as previously reported (16), and CRP was analyzed with the COBAS C11 (Roche Applied Science).

\section{Determination of Antioxidant Activity and Total Polyphenols}

Antioxidant activity of plasma was evaluated by ORAC (11), and the total polyphenol concentration was determined in plasma using the Folin-Ciocalteu method (12). 


\section{Peripheral Blood Mononuclear Cell Gene Expression by Quantitative Real-Time PCR}

Total RNA was extracted from peripheral blood mononuclear cells (PBMC) using TRIzol according to the manufacturer's instructions. The mRNA abundance was measured by realtime quantitative PCR using SYBR $^{\circledR}$ Premix, using actin as a reference for normalization. The primers are listed in Supplementary Table 1 . The relative expression was calculated using the $\Delta \Delta \mathrm{Ct}$ method (17).

\section{Statistical Analysis}

Continuous variables were evaluated using the KolmogorovSmirnov test to analyze the type of distribution. Wilcoxon tests were performed for paired samples to compare the medians of the lipid profile, glucose, CRP, antioxidant activity, oxidative markers, and body weight at baseline and after the intervention. For gene expression, logarithmic transformation was performed before analysis with a dependent-samples $t$-test. A value of $P$ $<0.05$ was considered significant. Correlations between two variables were evaluated by Spearman's test. Data are presented as the mean \pm standard deviation (SD) or standard error of the mean (SEM); or medians and 95\% confidence intervals (95\% CI). Data were analyzed using SPSS version 25 software for Macintosh (IBM Corp., Armonk, NY, USA).

\section{RESULTS}

\section{Analysis of Chemical Composition and Identification of Bioactive Compounds in Chaya Beverage}

The Chaya beverage mainly contained protein, fiber, and minerals (Table 1). Its antioxidant activity was $807 \pm 10.53$ Trolox equivalents ( $\mu$ moles/L), and the concentration of polyphenols was $1,359 \pm 47.2 \mathrm{mg}$ of gallic acid equivalents (GAE)/L. The HPLC profile obtained showed a pattern with two peaks that represented the quercetin and kaempferol present in Chaya (Figure 2). The retention time of quercetin was determined at $6.39 \mathrm{~min}$ and kaempferol at $9.75 \mathrm{~min}$. The concentration of quercetin in the Chaya beverage was $0.21 \pm$ $0.008 \mathrm{mg} / \mathrm{mL}$ and kaempferol was $1.72 \pm 0.015 \mathrm{mg} / \mathrm{mL}$.

\section{Anthropometric Parameters, Blood Pressure, and Glucose Concentration in Subjects With Dyslipidemia}

A total of 112 participants were screened, and 30 subjects were enrolled. The study population had a mean age of $42.5 \pm 10.8$ years, and $46.7 \%(n=14)$ were male. At baseline, subjects had a body mass index (BMI) of $29.2 \pm 4.41 \mathrm{~kg} / \mathrm{m}^{2}$, and blood glucose of 89.1 (95\% CI, 74.2-127) $\mathrm{mg} / \mathrm{dL}$. was 115 (95\% CI, 98-180) and 74 (95\% CI, 59-180) mmHg, respectively. After 6 weeks of the dietary strategy, the subjects with dyslipidemia who consumed the Chaya beverage exhibited a decrease in systolic BP $(-3.5 \%)(P<0.05)$ (Table 2). However, diastolic $\mathrm{BP}$, glucose concentration, body weight, and BMI did not show differences after intervention. At the end of the study, a percentage of $94 \pm 5.1$ of adherence to the intervention was
TABLE 1 | Chemical composition of the beverage Chaya. Data are expressed as a portion of daily intake $(20 \mathrm{~g} / 500 \mathrm{~mL})$. Values represent the mean \pm SEM.

\begin{tabular}{lc}
\hline & $\begin{array}{c}\text { Content } \\
\mathbf{( g / 5 0 0 ~} \mathbf{~ m L})\end{array}$ \\
\hline Protein & $1.02 \pm 0.02$ \\
Carbohydrates & $0.59 \pm 0.05$ \\
Fiber & $0.58 \pm 0.03$ \\
Minerals & $0.38 \pm 0.01$ \\
Lipids & $0.18 \pm 0.02$
\end{tabular}

reported. The consumption of Chaya did not have adverse effects in the participants.

\section{Lipid Profiles in Subjects Before and After Chaya Beverage Intervention}

The subjects with dyslipidemia included in this study showed lipid alterations in TG (208 mg/dL; 95\% CI, 114-301) and LDLC (121 mg/dL; 95\% CI, 72.7-200). After consuming Chaya for 6 weeks, there was a significant reduction of $20.6 \%$ in the concentration of TG $(P<0.05)$ (Table 2$)$. In contrast, circulating levels of TC, LDL-C, and HDL-C did not show differences after Chaya consumption.

\section{Chaya Consumption Enhanced Antioxidant Activity in Subjects With Dyslipidemia}

Interestingly, the antioxidant activity increased in plasma from 1324 Trolox equivalents ( $\mu$ moles/mL) (95\% CI, 963-2078) to 1485 (95\% CI, 1160-2416) $(P<0.05)$ (Figure 3A). This was accompanied by a significant increase of $4 \%$ in the plasma polyphenol concentration $(P<0.005)$ (Figure 3B). Furthermore, subjects with dyslipidemia showed an inverse correlation between plasma polyphenols and serum TG ( $r=$ $-0.367, P=0.047$; Figure 4A).

\section{Chaya Intake Decreased in Oxidative Marker MDA}

Notably, the 6-week Chaya intervention reduced the MDA concentration by $80.4 \%(P<0.0001)$ (Figure 3C) with no changes in the inflammatory marker CRP (Figure 3D). There is evidence of a relationship between OS and inflammation and the development of CVD and mortality $(18,19)$.

\section{Differential Expression in Peripheral Blood Mononuclear Cells of Antioxidant and Lipid Metabolism Genes Resulting From Chaya Consumption in Subjects With Dyslipidemia}

As expected, the antioxidant enzyme CAT showed a significant increase after Chaya intake $(P<0.001)$ without changes in the expression of SOD1 (Figures 5A,B) in PBMC. In fact, there was a positive correlation between the gene expression of CAT and plasma antioxidant activity $(r=0.380, P=0.046$; Figure 4B). In addition, the expression of lipid-related genes 


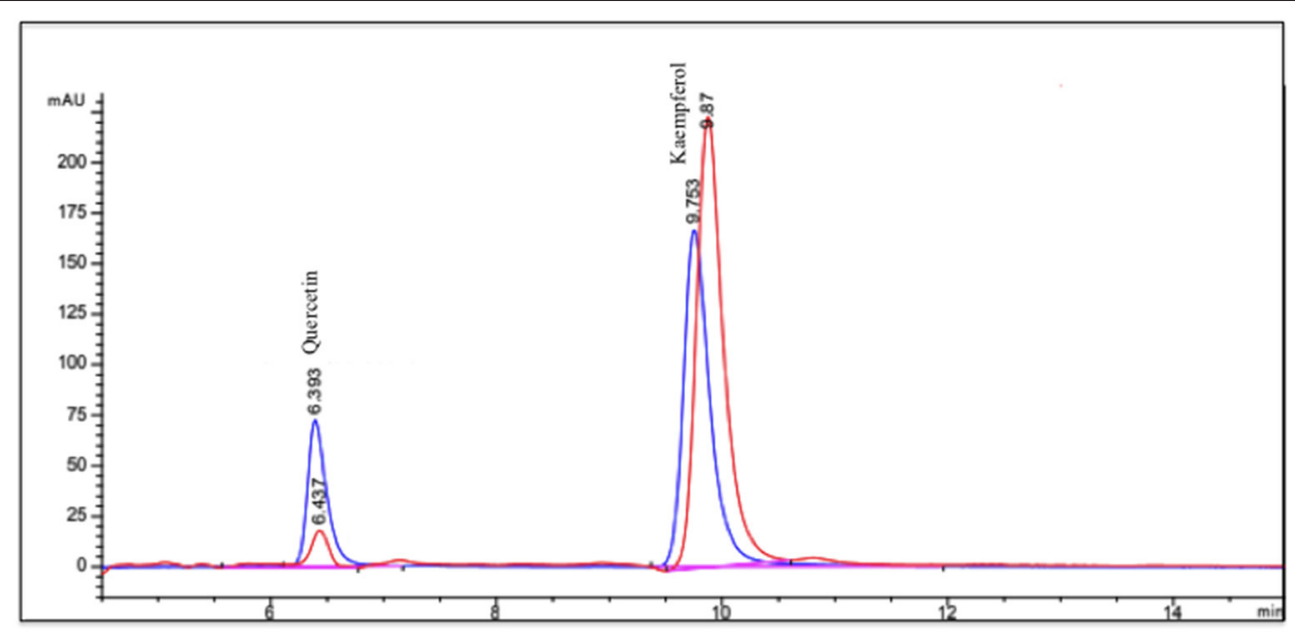

FIGURE 2 | HPLC profile of Chaya. Principal compounds in Chaya are quercetin (6.43 min) and kaempferol (9.87 min) (red line).

TABLE 2 | Anthropometric characteristics, blood pressure, and biochemical parameters at baseline and after intervention with Chaya.

\begin{tabular}{lccc}
\hline Characteristic & Baseline & Week 6 & $P$-value \\
\hline Weight (kg) & $72.2(50.4-115)$ & $72.3(50.1-117)$ & 0.050 \\
BMl (kg/m²) & $29.2 \pm 4.41$ & $29.1 \pm 4.41$ & 0.160 \\
Circumference of waist (cm) & $93(74.1-120)$ & $93(72.8-118)$ & 0.292 \\
WHtR & $0.58(0.46-0.69)$ & $0.59(0.48-0.68)$ & 0.791 \\
Systolic BP (mmHg) & $115(98-180)$ & $112(93.4-166)$ & 0.032 \\
Diastolic BP (mmHg) & $74(59-180)$ & $73(61.7-106)$ & 0.992 \\
Glucose (mg/dL) & $89.1(74.2-127)$ & $91.9(80.1-107)$ & 0.052 \\
Triglycerides (mg/dL) & $208(114-301)$ & $166(90-328)$ & 0.049 \\
TC (mg/dL) & $188(143-264)$ & $186(149-260)$ & 0.133 \\
HDL-C (mg/dL) & $39.7(27.6-70.3)$ & $41.5(28.9-58.7)$ & 0.425 \\
LDL-C (mg/dL) & $121(72.7-200)$ & $120(95.1-185)$ & 0.632 \\
\hline
\end{tabular}

Values represent the mean $\pm S D$ or median ( $95 \%$ confidence interval). Body mass index, (BMI); Waist-to-height ratio (WHtR); Blood pressure (BP); Total cholesterol (TC); Highdensity lipoprotein cholesterol (HDL-C); Low-density lipoprotein cholesterol (LDL-C). Statistical analysis was determined by the Wilcoxon test or dependent-samples $t$-test.

was evaluated. After the consumption of Chaya, there was a significant decrease in the gene expression of HMGCR (hydroxymethyl-glutaryl coenzyme A reductase) in PBMC, which is involved in hepatic cholesterol synthesis (Figure 5C), and this decrease was accompanied by an increase in the gene expression of $A B C A 1$ (ATP-binding cassette transporter A1) (Figure 5D), which mediates the efflux of cholesterol to regulate lipid levels.

\section{DISCUSSION}

Our results demonstrated that a nutritional strategy that includes the consumption of a Chaya beverage for 6 weeks reduced plasma triglyceride concentration and lipoperoxidation, increased plasma antioxidant activity, and modulated the

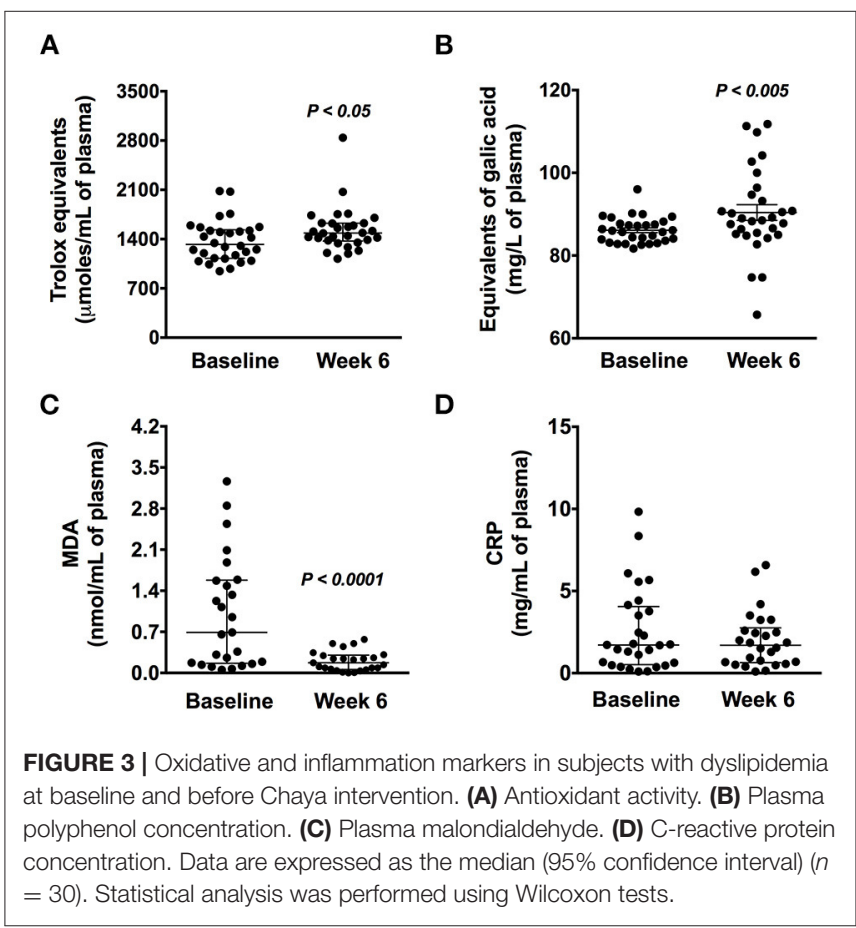

expression of antioxidant and lipid metabolism genes in PBMC in subjects with dyslipidemia.

Residents in middle-income countries experience health disparities and less healthy eating patterns; thus, it is very common for inhabitants to use traditional foods or herbs to control different types of diseases. Chaya leaves are used in Mayan traditional medicine to treat kidney stones, diabetes, and high BP; infusions or teas make its administration from Chaya leaves. However, communities use native food components to control several diseases mainly based on empirical knowledge of their effects on health (20). The relevance of our work resides 


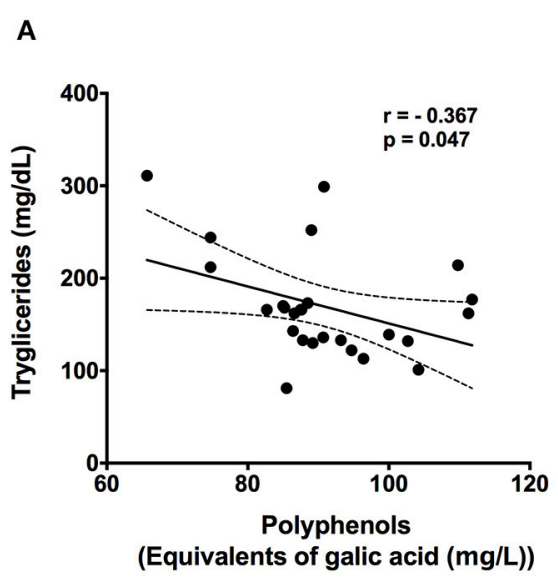

B

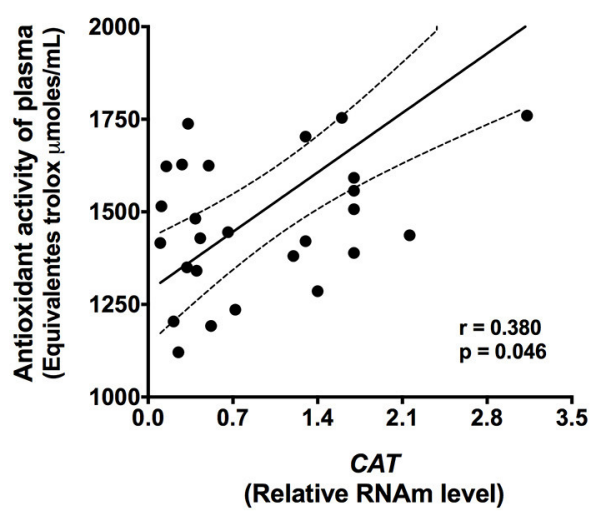

FIGURE 4 | Correlations between serum triglycerides and plasma polyphenols (A) and between plasma antioxidant activity and CAT gene expression (B) $(n=30)$. Statistical analysis was performed by Spearman's test ( $95 \%$ confidence interval).

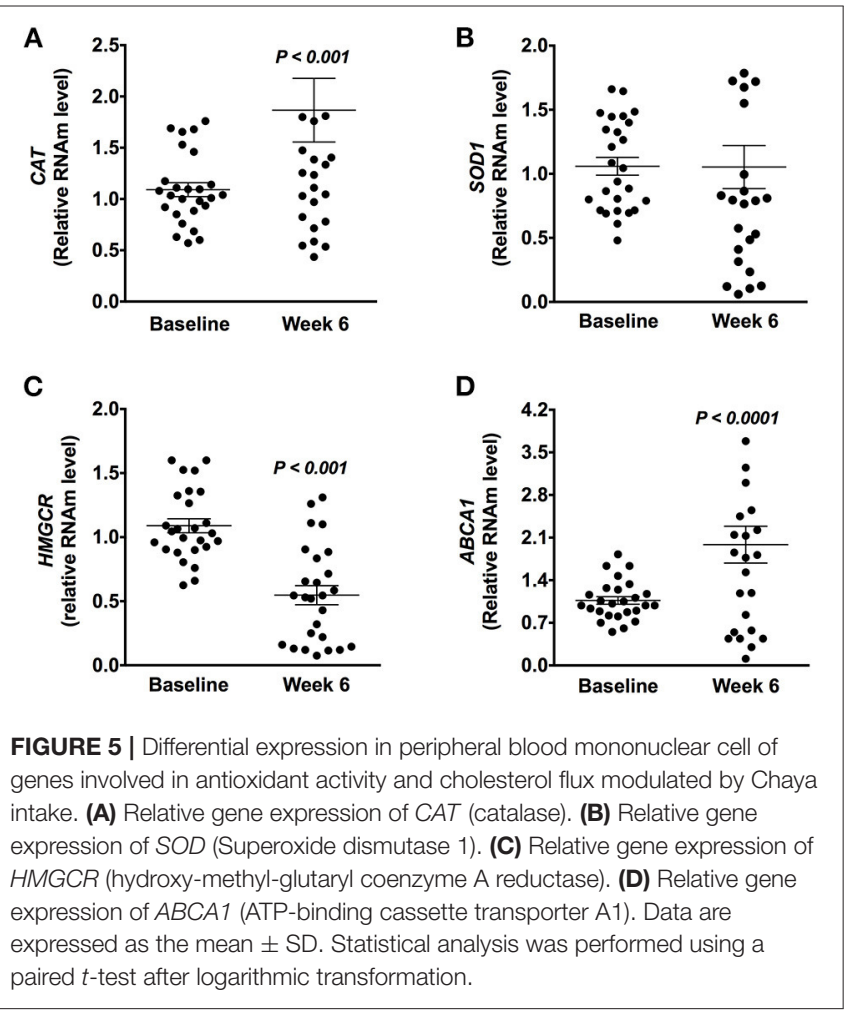

in the evaluation of a dietary strategy that included the use of Chaya, an inexpensive and native regional food, to decrease lipid alterations. A few studies in vitro and in animal models have demonstrated antioxidant, anti-inflammatory, hypoglycemic, and hypolipidemic effects of Chaya $(8,21)$. In fact, a study in rats showed that doses of $0.5-1.5 \mathrm{mg} / \mathrm{kg}$ of Chaya extracts administered intragastrically decreased the concentrations of TG and TC (9). Interestingly, in the present study, we observed an inverse correlation between plasma polyphenols and serum TG, supporting the hypothesis that the hypolipidemic effects of Chaya consumption may be attributed to its effect on polyphenols. This lipid-lowering effect promoted by polyphenols could be attributed to the activation of AMP-activated protein kinase (AMPK) and inactivation of acetyl-CoA carboxylase, which in turn promotes reduced fatty acid synthesis and increased fatty acid oxidation (22). In vitro and in vivo studies have shown that polyphenols, such as quercetin and kaempferol, reduce plasma TG by regulating fatty acid mobilization and triglyceride synthesis (23-25). In addition, AMPK activation also involves an increase in energy expenditure, reduction in lipogenesis, and reduction in fat mass and OS through activation of its energetic sensors (26-28). However, the effects of polyphenols in our study were not associated with changes in body weight, which could be attributed to the dose used or to the time of intervention. The lack of effect on BMI has been previously observed with an intervention with $300 \mathrm{~mL}$ of blackberry juice drunk daily for 8 weeks (29). Conversely, our results suggest that the hypolipidemic effects of Chaya may also be related to the antioxidant effects of polyphenols. Studies have shown that persistent ROS generation is involved in lipid dysregulation caused by decreased fatty acid uptake, lipogenesis, and $\beta$ oxidation of fatty acids $(30,31)$. In fact, one study showed a statistically significant correlation between the oxidative stress index and serum cholesterol $(p<0.001 ; r=0.596)$ and triglycerides $(p<0.001 ; r=0.476)$ (32). Thus, the antioxidant activity of polyphenols reduces ROS production and also the increase of endogenous antioxidants ameliorates hyperlipidemia and the alterations of many cell or tissue types caused by OS in hyperlipidemia (33).

Our work is the first study conducted in humans to show the clinical hypotriglyceridemic and antioxidant effect of Chaya consumption. Notably, consumption of the Chaya beverage $(40 \mathrm{~g} / \mathrm{L})$ showed antioxidant activity. These results are similar to the antioxidant effect resulting from the consumption of most antioxidant-rich foods, which are reference sources of polyphenols and widely known for their health-promoting properties (34-38). For example, one study demonstrated that 
intervention with Mate tea (1L/day) for 90 days promoted a significant increase in serum antioxidant activity compared to baseline levels in the population with dyslipidemia $(P<0.05)$ (35). Another study demonstrated a significant increase in total antioxidant capacity in subjects with hypercholesterolemia by daily consumption of red wine $(125 \mathrm{~mL}$ for women or $250 \mathrm{~mL}$ for men) for 1 month (36). Another popular beverage that showed a similar antioxidant effect is coffee; its consumption ( $600 \mathrm{~mL} /$ day) for 8 weeks increased plasma antioxidant activity in subjects with hypercholesterolemia (37). In addition, orange juice consumption $(750 \mathrm{~mL} /$ day) for 8 weeks increased antioxidant activity and decreased TC in overweight subjects (38). This is important as it has been shown that not all interventions involving antioxidant foods in subjects with dyslipidemia generated an effect on circulating antioxidant activity (39). This types of foods have received considerable attention because of their potential antioxidant activity by hydroxyl groups and double bonds in chemical structure of polyphenols (40). In addition, the consumption of different foods with high concentrations of polyphenols, such as beverages made from fruits and vegetables (41), blackberry juice (29) and red grapes (42), showed a significant reduction in the lipid profile of subjects with dyslipidemia. Despite the beneficial effects of these foods on dyslipidemia, most of them are not always accessible to different communities in accordance with their annual availability or to the lifestyle and traditions of the population of those communities. Therefore, based on our results, Chaya represent a low-cost nutritional strategy against dyslipidemias in subjects with access to this plant such as families in the state of Yucatan and also throughout Central America (43).

Interestingly, we observed that consumption of Chaya not only increased antioxidant activity but also decreased the levels of MDA in subjects with dyslipidemia, suggesting a protective effect against OS. Other foods that have been extensively studied for their antioxidant activity and reduction of the oxidative damage in lipids are orange juice $(-55 \%)$ and coffee $(-10.3 \%)$ $(37,38)$. The antioxidant activity of polyphenols can suppress the oxidative modification of plasma lipids and lipoproteins, which are major targets of many antiatherogenic agents and the preferable strategy to prevent the development of CVD. Furthermore, polyphenols, such as quercetin and kaempferol, which are also present in Chaya, can act by activating the transcription factor Nrf2, which travels to the nucleus to bind to the antioxidant response element sequence and induce the expression of genes of the endogenous antioxidant system such as CAT and SOD (44). Our results demonstrated that Chaya consumption induced an increase in CAT gene expression in PBMC, which is in agreement with previous evidence that dietary intervention with food rich in antioxidants can modulate antioxidant enzymes in subjects with dyslipidemia; for example, the consumption of the traditional Chinese herb Graptopetalum paraguayense significantly increased the enzymatic activity of glutathione peroxidase and CAT (45), and aqueous wolfberry fruit intake enhanced the activity of CAT (46). These results suggest that polyphenols present in Chaya contribute to maintaining the redox homeostasis of cells through the activation of antioxidant enzymes. Although an increase of polyphenols in plasma induced the antioxidant machinery, it was not enough to generate a decrease in inflammatory marker CRP, which could be attributed to the doses of the bioactive compound in Chaya. The anti-inflammatory effect is directly dependent of the doses of polyphenols. In fact, a systematic review and metaanalysis showed a tendency toward lower serum concentrations of inflammatory biomarkers only at dose of $>200 \mathrm{mg}$ /day of polyphenols from grapes (31) and only $90 \mathrm{mg}$ in plasma (47).

PBMC gene expression could be used as a tool to assess potential markers of the mechanism of action of the intervention. Indeed, one study demonstrated that statins can regulate gene expression in PBMCs from patients with dyslipidemia before detectable changes in lipid profile occur (48). The intervention with Chaya significantly regulated $H M G C R$ and $A B C A 1$ gene expression in PBMC, despite no differences observed in serum total cholesterol in our participants, such as was found for TG. In this sense, recent studies have suggested a function for $A B C A 1$, especially macrophage $A B C A 1$, in lipid metabolism (49). Evidence showed that gene expression of ABCA1 is induced during differentiation of monocytes into macrophages and up-regulated by cholesterol influx. The proposed molecular mechanism is the induction of $A B C A 1$ gene expression by peroxisome proliferator-activated receptors $-\alpha$ and $-\gamma$ in human macrophages and macrophage-derived foam cells, which promotes increased cholesterol flow from macrophages to the liver (50). Thus, this process could be control susceptibility to macrophage recruitment into different tissues and development of atherosclerosis (51).

Our results on the antioxidant and hypotriglyceridemic effects of Chaya consumption are very interesting. However, this study has some limitations, such as the study design and the small sample size. This type of study did not include a control group and age of participants was highly variable, but they are useful as a first approximation to evaluate the feasibility and acceptability of interventions. In addition, some factors that may affect the outcome measurements, such as dietary caloric restriction, were not examined in the present study. However, the intention of the study was to evaluate the effect of this intervention without modifying the lifestyle of the participants, which contributes to know the effect of Chaya and not of the other modifications that could have been suggested to the population. Thus it remains to be explored whether the findings of this study can be applied to other groups.

\section{CONCLUSION}

Altogether, our results demonstrate that consumption of Chaya has hypotriglyceridemic and antioxidant effects in subjects with dyslipidemia.

\section{DATA AVAILABILITY STATEMENT}

The datasets generated for this study are available on request to the corresponding author. 


\section{ETHICS STATEMENT}

This study involving human participants was reviewed and approved by the Ethics Committee of the Hospital Regional de Alta Especialidad de la Península de Yucatán (No. 2018-030) and Instituto Nacional de Pediatría (No. 2019/03). The participants provided their written informed consent to participate in this study.

\section{AUTHOR CONTRIBUTIONS}

MG-C, IM-V, and AA-N designed the study. TC-C, YC-C, CM-M, and JT-G performed the experiments. CP-M, RL, and AG-S analyzed the data. AA-N, IM-V, NT, and AT wrote the paper. All authors contributed to the manuscript.

\section{FUNDING}

Monetary sponsorship was received from Hospital Regional de Alta Especialidad de la Península de Yucatán, Mérida, Yucatán.

\section{REFERENCES}

1. Park K, Gross M, Lee DH, Holvoet P, Himes JH, Shikany JM, et al. Oxidative stress and insulin resistance: the coronary artery risk development in young adults study. Diabetes Care. (2009) 32:1302-7. doi: 10.2337/dc09-0259

2. Viigimaa M, Abina J, Zemtsovskaya G, Tikhaze A, Konovalova G, Kumskova E, et al. Malondialdehyde-modified low-density lipoproteins as biomarker for atherosclerosis. Blood Press. (2010) 19:164-8. doi: $10.3109 / 08037051.2010 .484158$

3. Pedro T, Martinez-Hervas S, Tormo C, Garcia-Garcia AB, SaezTormo G, Ascaso JF, et al. Oxidative stress and antioxidant enzyme values in lymphomonocytes after an oral unsaturated fat load test in familial hypercholesterolemic subjects. Transl Res. (2013) 161:50-6. doi: 10.1016/j.trsl.2012.09.002

4. Scognamiglio M, Costa D, Sorriento A, Napoli C. Current drugs and nutraceuticals for the treatment of patients with dyslipidemias. Curr Pharm Des. (2019) 25:85-95. doi: 10.2174/1381612825666190130101108

5. Kuti JO, Torres ES. Potential nutritional and health benefits of tree spinach. Progress New Crops. (1996) 13:516-20.

6. Perez-Gonzalez MZ, Macias-Rubalcava ML, Hernandez-Ortega S, SiordiaReyes AG, Jimenez-Arellanes MA. Additional compounds and the therapeutic potential of Cnidoscolus chayamansa (McVaugh) against hepatotoxicity induced by antitubercular drugs. Biomed Pharmacother. (2019) 117:109140. doi: 10.1016/j.biopha.2019.109140

7. Pillai KK, Chidambaranathan N, Halith MM, Jayaprakash S, Narayanan N. Anti-hyperglycemic effect of alcoholic extracts of Cnidoscolus chayamansa in experimental diabetes and their effects on key metabolic enzymes involved in carbohydrate metabolism. Int J Res Pharm Chem. (2012) 2:179-87.

8. Garcia-Rodriguez RV, Gutierrez-Rebolledo GA, Mendez-Bolaina E, SanchezMedina A, Maldonado-Saavedra O, Dominguez-Ortiz MA, et al. Cnidoscolus chayamansa Mc Vaugh, an important antioxidant, anti-inflammatory and cardioprotective plant used in Mexico. J Ethnopharmacol. (2014) 151:937-43. doi: 10.1016/j.jep.2013.12.004

9. Miranda-Velasquez L, Oranday-Cardenas A, Lozano-Garza H, Rivas-Morales C, Chamorro-Cevallos G, Cruz-Vega DE. Hypocholesterolemic activity from the leaf extracts of Cnidoscolus chayamansa. Plant Foods Hum Nutr. (2010) 65:392-5. doi: 10.1007/s11130-010-0202-4

10. Helrich K, Horwitz W, Williams S. Official Methods of Analysis of the Association of Official Analytical Chemists: Changes in Official Methods of Analysis of AOAC International. Suppl. to the 15. Ed. 5: AOAC. Arlington (1994).

11. Huang D, Ou B, Hampsch-Woodill M, Flanagan JA, Prior RL. Highthroughput assay of oxygen radical absorbance capacity (ORAC) using a
The edition style of this article was support by Universidad Modelo, Mérida, Yucatán.

\section{ACKNOWLEDGMENTS}

We thank José L. Tapia-Muñoz, from the Natural Resources Unit at the Centro de Investigación Científica de Yucatán, for the identification and authentication of Chaya leaves. We thank Priscila Villanueva Luna for her support with the participants, as well as Victor Fernando Villanueva Abuxapqui for allowing us the use of areas to carry out the project, and Lilia G. Noriega for critical reading of our manuscript. A special acknowledgment to my husband Evander Ponce Vargas for his support in this project.

\section{SUPPLEMENTARY MATERIAL}

The Supplementary Material for this article can be found online at: https://www.frontiersin.org/articles/10.3389/fnut.2021. 666243/full\#supplementary-material

multichannel liquid handling system coupled with a microplate fluorescence reader in 96-well format. J Agric Food Chem. (2002) 50:4437-44. doi: 10.1021/jf0201529

12. Koren E, Kohen R, Ginsburg I. Polyphenols enhance total oxidant-scavenging capacities of human blood by binding to red blood cells. Exp Biol Med (Maywood). (2010) 235:689-99. doi: 10.1258/ebm.2010.009370

13. Zu Y, Li C, Fu Y, Zhao C. Simultaneous determination of catechin, rutin, quercetin kaempferol and isorhamnetin in the extract of sea buckthorn (Hippophae rhamnoides L.) leaves by RP-HPLC with DAD. J Pharm Biomed Anal. (2006) 41:714-9. doi: 10.1016/j.jpba.2005.04.052

14. Messina D, Soto C, Mendez A, Corte C, Kemnitz M, Avena V, et al. Lipid lowering effect of mate tea intake in dyslipidemic subjects. Nutr Hosp. (2015) 31:2131-9. doi: 10.3305/nh.2015.31.5.8386

15. Lohman TG, Roche AF, Martorell R. Anthropometric Standardization Reference Manual. Champaign, IL: Human Kinetics Books Champaign (1988).

16. Gerard-Monnier D, Erdelmeier I, Regnard K, Moze-Henry N, Yadan JC, Chaudiere J. Reactions of 1-methyl-2-phenylindole with malondialdehyde and 4-hydroxyalkenals. Analytical applications to a colorimetric assay of lipid peroxidation. Chem Res Toxicol. (1998) 11:1176-83. doi: 10.1021/tx97 01790

17. Pfaffl MW. A new mathematical model for relative quantification in real-time RT-PCR. Nucleic Acids Res. (2001) 29:e45. doi: 10.1093/nar/29.9.e45

18. Xuan Y, Bobak M, Anusruti A, Jansen EH, Pajak A, Tamosiunas A, et al. Association of serum markers of oxidative stress with myocardial infarction and stroke: pooled results from four large European cohort studies. Eur $J$ Epidemiol. (2019) 34:471-81. doi: 10.1007/s10654-018-0457-x

19. Xuan Y, Gào X, Holleczek B, Brenner H, Schöttker B. Prediction of myocardial infarction, stroke and cardiovascular mortality with urinary biomarkers of oxidative stress: results from a large cohort study. Int J Cardiol. (2018) 273:223-9. doi: 10.1016/j.ijcard.2018.08.002

20. Lopez-Romero P, Pichardo-Ontiveros E, Avila-Nava A, Vazquez-Manjarrez $\mathrm{N}$, Tovar AR, Pedraza-Chaverri J, et al. The effect of nopal (Opuntia ficus indica) on postprandial blood glucose, incretins, and antioxidant activity in Mexican patients with type 2 diabetes after consumption of two different composition breakfasts. J Acad Nutr Diet. (2014) 114:1811-8. doi: 10.1016/j.jand.2014.06.352

21. Loarca-Pina G, Mendoza S, Ramos-Gomez M, Reynoso R. Antioxidant, antimutagenic, and antidiabetic activities of edible leaves from Cnidoscolus chayamansa Mc Vaugh. J Food Sci. (2010) 75:H68-72. doi: 10.1111/j.1750-3841.2009.01505.x

22. Gasparrini M, Giampieri F, M Alvarez Suarez J, Mazzoni L, Y Forbes Hernandez T, L Quiles J, et al. AMPK as a new attractive therapeutic target for disease prevention: the role of dietary compounds 
AMPK and disease prevention. Curr Drug Targets. (2016) 17:865-89. doi: 10.2174/1573399811666150615150235

23. Gomez-Zorita S, Lasa A, Abendaño N, Fernandez-Quintela A, MosquedaSolís A, Garcia-Sobreviela MP, et al. Phenolic compounds apigenin, hesperidin and kaempferol reduce in vitro lipid accumulation in human adipocytes. $J$ Transl Med. (2017) 15:1-10. doi: 10.1186/s12967-017-1343-0

24. Kuipers EN, Dam ADv, Held NM, Mol IM, Houtkooper RH, Rensen PC, et al. Quercetin lowers plasma triglycerides accompanied by white adipose tissue browning in diet-induced obese mice. Int J Mol Sci. (2018) 19:1786. doi: 10.3390/ijms19061786

25. Seo M-J, Lee Y-J, Hwang J-H, Kim K-J, Lee B-Y. The inhibitory effects of quercetin on obesity and obesity-induced inflammation by regulation of MAPK signaling. J Nutr Biochem. (2015) 26:1308-16. doi: 10.1016/j.jnutbio.2015.06.005

26. Eo H, Jeon Y-j, Lee M, Lim Y. Brown Alga Ecklonia cava polyphenol extract ameliorates hepatic lipogenesis, oxidative stress, and inflammation by activation of AMPK and SIRT1 in high-fat diet-induced obese mice. J Agric Food Chem. (2015) 63:349-59. doi: 10.1021/jf502830b

27. Luna-Vital D, Luzardo-Ocampo I, Cuellar-Nuñez ML, Loarca-Piña G, de Mejia EG. Maize extract rich in ferulic acid and anthocyanins prevents highfat-induced obesity in mice by modulating SIRT1, AMPK and IL-6 associated metabolic and inflammatory pathways. J Nutr Biochem. (2020) 79:108343. doi: $10.1016 /$ j.jnutbio.2020.108343

28. Liu L, Yasen M, Tang D, Ye J, Aisa HA, Xin X. Polyphenol-enriched extract of Rosa rugosa Thunb regulates lipid metabolism in diabetic rats by activation of AMPK pathway. Biomed Pharmacother. (2018) 100:29-35. doi: 10.1016/j.biopha.2018.01.143

29. Aghababaee SK, Vafa M, Shidfar F, Tahavorgar A, Gohari M, Katebi D, et al. Effects of blackberry (Morus nigra L.) consumption on serum concentration of lipoproteins, apo AI, apo B, and high-sensitivity-C-reactive protein and blood pressure in dyslipidemic patients. J Res Med Sci. (2015) 20:684. doi: 10.4103/1735-1995.166227

30. Hassan W, Rongyin G, Daoud A, Ding L, Wang L, Liu J, et al. Reduced oxidative stress contributes to the lipid lowering effects of isoquercitrin in free fatty acids induced hepatocytes. Oxid Med Cell Longev. (2014) 2014:313602. doi: $10.1155 / 2014 / 313602$

31. Huc L, Lemarié A, Guéraud F, Héliès-Toussaint C. Low concentrations of bisphenol A induce lipid accumulation mediated by the production of reactive oxygen species in the mitochondria of HepG2 cells. Toxicol In Vitro. (2012) 26:709-17. doi: 10.1016/j.tiv.2012.03.017

32. Turkdogan KA, Akpinar O, Karabacak M, Akpinar H, Turkdogan FT, Karahan O. Association between oxidative stress index and serum lipid levels in healthy young adults. J Pak Med Assoc. (2014) 64:379-81.

33. Meydani M, Hasan ST. Dietary polyphenols and obesity. Nutrients. (2010) 2:737-51. doi: 10.3390/nu2070737

34. Ninfali P, Chiarabini A, Angelino D. The ORAC/kcal ratio qualifies nutritional and functional properties of fruit juices, nectars, and fruit drinks. Int J Food Sci Nutr. (2014) 65:708-12. doi: 10.3109/09637486.2014.918591

35. Boaventura BCB, Di Pietro PF, Stefanuto A, Klein GA, de Morais EC, de Andrade F, et al. Association of mate tea (Ilex paraguariensis) intake and dietary intervention and effects on oxidative stress biomarkers of dyslipidemic subjects. Nutrition. (2012) 28:657-64. doi: 10.1016/j.nut.2011.10.017

36. Apostolidou C, Adamopoulos K, Lymperaki E, Iliadis S, Papapreponis P, Kourtidou-Papadeli C. Cardiovascular risk and benefits from antioxidant dietary intervention with red wine in asymptomatic hypercholesterolemics. Clin Nutr ESPEN. (2015) 10:e224-33. doi: 10.1016/j.clnesp.2015.08.001

37. Martinez-Lopez S, Sarria B, Mateos R, Bravo-Clemente L. Moderate consumption of a soluble green/roasted coffee rich in caffeoylquinic acids reduces cardiovascular risk markers: results from a randomized, cross-over, controlled trial in healthy and hypercholesterolemic subjects. Eur J Nutr. (2019) 58:865-78. doi: 10.1007/s00394-018-1726-x

38. Dourado GK, Cesar TB. Investigation of cytokines, oxidative stress, metabolic, and inflammatory biomarkers after orange juice consumption by normal and overweight subjects. Food Nutr Res. (2015) 59:28147. doi: $10.3402 /$ fnr.v59.28147

39. Medina-Vera I, Gómez-de-Regil L, Gutiérrez-Solis AL, Lugo R, Guevara-Cruz M, Pedraza-Chaverri J, et al. Dietary strategies by foods with antioxidant effect on nutritional management of dyslipidemias: a systematic review. Antioxidants. (2021) 10:225. doi: 10.3390/antiox10020225
40. Carlsen MH, Halvorsen BL, Holte K, Bøhn SK, Dragland S, Sampson L, et al. The total antioxidant content of more than 3100 foods, beverages, spices, herbs and supplements used worldwide. Nutr J. (2010) 9:3. doi: 10.1186/1475-2891-9-3

41. Chiu H-F, Chen Y-J, Lu Y-Y, Han Y-C, Shen Y-C, Venkatakrishnan K, et al. Regulatory efficacy of fermented plant extract on the intestinal microflora and lipid profile in mildly hypercholesterolemic individuals. J Food Drug Anal. (2017) 25:819-27. doi: 10.1016/j.jfda.2016.10.008

42. Rahbar AR, Mahmoudabadi MMS, Islam MS. Comparative effects of red and white grapes on oxidative markers and lipidemic parameters in adult hypercholesterolemic humans. Food Funct. (2015) 6:1992-8. doi: $10.1039 / \mathrm{C} 5 \mathrm{FO} 00100 \mathrm{E}$

43. Ross-Ibarra J, Molina-Cruz A. The ethnobotany of Chaya (Cnidoscolus aconitifoliusSSP. Aconitifoliusbreckon) La Etnobotanica de Chaya (Cnidoscolus aconitifoliusssp. aconitifoliusBreckon): a nutritious Maya Vegetable Una Verdura Nutritiva Maya. Econ Bot. (2002) 56:350-65. doi: 10. 1663/0013-0001(2002)056[0350:TEOCCA]2.0.CO;2

44. Khurana S, Venkataraman K, Hollingsworth A, Piche M, Tai TC. Polyphenols: benefits to the cardiovascular system in health and in aging. Nutrients. (2013) 5:3779-827. doi: 10.3390/nu5103779

45. Yu-Ling L, Hsin-Yi P, Hui-Min H, Ching-Hsiu L, Su-Tze C. Effects of Graptopetalum paraguayense consumption on serum lipid profiles and antioxidative status in hypercholesteremic subjects. J Sci Food Agric. (2011) 91:1230-5. doi: 10.1002/jsfa.4304

46. Lee YJ, Ahn Y, Kwon O, Lee MY, Lee CH, Lee S, et al. Dietary wolfberry extract modifies oxidative stress by controlling the expression of inflammatory mRNAs in overweight and hypercholesterolemic subjects: a randomized, double-blind, placebo-controlled trial. J Agric Food Chem. (2017) 65:309-16. doi: 10.1021/acs.jafc.6b04701

47. Haghighatdoost F, Gholami A, Hariri M. Effect of grape polyphenols on selected inflammatory mediators: a systematic review and meta-analysis randomized clinical trials. EXCLI J. (2020) 19:251-67. doi: $10.17179 /$ excli2020-1011

48. Wibaut-Berlaimont V, Randi A, Mandryko V, Lunnon M, Haskard D, Naoumova R. Atorvastatin affects leukocyte gene expression in dyslipidemia patients: in vivo regulation of hemostasis, inflammation and apoptosis. $J$ Thromb Haemost. (2005) 3:677-85. doi: 10.1111/j.1538-7836.2005.01211.x

49. Schmitz G, Kaminski W, Porsch-Özcürümez M, Klucken J, Orso E, Bodzioch $\mathrm{M}$, et al. ATP-binding cassette transporter A1 (ABCA1) in macrophages: a dual function in inflammation and lipid metabolism? Pathobiology. (1999) 67:236-40. doi: 10.1159/000028100

50. Chinetti G, Lestavel S, Bocher V, Remaley AT, Neve B, Torra IP, et al. PPAR- $\alpha$ and PPAR- $\gamma$ activators induce cholesterol removal from human macrophage foam cells through stimulation of the ABCA1 pathway. Nat Med. (2001) 7:53-8. doi: 10.1038/83348

51. Van Eck M, Bos IST, Kaminski WE, Orsó E, Rothe G, Twisk J, et al. Leukocyte $\mathrm{ABCA} 1$ controls susceptibility to atherosclerosis and macrophage recruitment into tissues. Proc Natl Acad Sci U S A. (2002) 99:6298-303. doi: $10.1073 /$ pnas.092327399

Conflict of Interest: The authors declare that the research was conducted in the absence of any commercial or financial relationships that could be construed as a potential conflict of interest.

Publisher's Note: All claims expressed in this article are solely those of the authors and do not necessarily represent those of their affiliated organizations, or those of the publisher, the editors and the reviewers. Any product that may be evaluated in this article, or claim that may be made by its manufacturer, is not guaranteed or endorsed by the publisher.

Copyright $\odot 2021$ Guevara-Cruz, Medina-Vera, Cu-Cañetas, Cordero-Chan, Torres, Tovar, Márquez-Mota, Talamantes-Gómez, Pérez-Monter, Lugo, Gutiérrez-Solis and Avila-Nava. This is an open-access article distributed under the terms of the Creative Commons Attribution License (CC BY). The use, distribution or reproduction in other forums is permitted, provided the original author(s) and the copyright owner(s) are credited and that the original publication in this journal is cited, in accordance with accepted academic practice. No use, distribution or reproduction is permitted which does not comply with these terms. 